\title{
PENERAPAN MEDIA SOSIAL SEBAGAI MEDIA PROMOSI USAHA TINGKAT UMKM DI KELURAHAN PAMULANG BARAT
}

\author{
Santosa Wijayanto ${ }^{*}$ \\ Jazuli Mukhtar 2 \\ Faishal Rahman ${ }^{3}$ \\ Ersi Putri Utami ${ }^{4}$ \\ Fitri Chintya ${ }^{5}$ \\ Nanda Rizky Pratama ${ }^{6}$ \\ Ramadhan Ari Saputra7 \\ Ade Suhendra ${ }^{8}$
} 1,2,3,4,5,6,7,8Universitas Pamulang, Banten, Indonesia dosen02683@unpam.ac.id ${ }^{1 *}$

Kata Kunci: [Media Sosial, Promosi, instagram]

Published by:

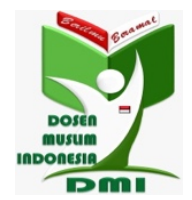

\begin{abstract}
Abstrak: Dewasa ini, teknologi informasi berkembang sangat pesat hingga sulit untuk dipisahkan dalam kehidupan seharihari, salah satu diantaranya adalah media elektronik. Segala jenis informasi dapat disebar luaskan melalui media elektronik, mulai dari berita informatif hingga promosi usaha. Media sosial merupakan salah satu dari banyak jenis media elektronik yang sangat populer di kalangan muda hingga tua. Hal tersebut disebabkan oleh adanya interaksi langsung yang masif antara pengguna satu dengan lainnya, karena alasan tersebut pula mengapa promosi di media sosial menjadi sangat efektif. Fitur gratis, dan adanya komunikasi lebih antara pelaku usaha dengan konsumen menciptakan kenyamanan tersendiri bagi kedua belah pihak. Masyarakat Kelurahan Pamulang Barat merupakan salah satu dari banyak masyarakat di lingkungan Universitas Pamulang yang belum benar-benar memanfaatkan media ini sebagai media promosi usaha mereka, sehingga diharapkan sosialisasi terhadap baiknya menerapkan media sosial sebagai media promosi usaha dapat mengurangi cost dalam promosi dan meningkatkan jangkauan konsumen yang lebih luas.
\end{abstract}

Copyright (C) 2021 The Author(s)

This article is licensed under CC BY 4.0 License (cc) Br 


\section{Pendahuluan}

Seiring perkembangan zaman, teknologi juga berkembang begitu pesat sehingga selalu adanya keterkaitan antara teknologi dengan manusia dalam berbagai aspek termasuk sebagai media promosi usaha tingkat UMKM. Usaha Mikro, Kecil, dan Menengah (UMKM) adalah kegiatan yang dapat mempreluas lapangan pekerjaan, dan berperan dalam proses pemerataan dan peningkatan pendapatan masyarakat. UMKM memiliki Undang-Undang tersendiri yaitu UU RI Nomor 20 tahun 2008 tentang Usaha Mikro, Kecil, dan Menengah yang disahkan oleh Presiden Dr. H. Susilo Bambang Yudhoyono pada tanggal 4 Juli 2008 di Jakarta.

Media sosial menjadi salah satu dari sekian banyak teknologi informasi yang berkembang pesat dan dapat dimanfaatkan sebagai media promosi bagi UMKM. Menurut dataportal.com, per Januari 2021, Indonesia memiliki 170 Juta pengguna aktif di media sosial. Hal ini dapat dimanfaatkan pelaku usaha tingkat UMKM untuk meningkatkan jangkauan konsumen dan minat konsumen terhadap produk atau jasa mereka. Pemasaran melalui media sosial akan memengaruhi faktor eksternal yang mempengaruhi persepsi konsumen akan sebuah produk, yang kemudian akan mempengaruhi minat beli konsumen (Maoyan et al, 2014).

Dari banyaknya media sosial yang banyak digunakan masyarakat Indonesia, Youtube, Whatsapp, dan Instagram merupakan 3 media sosial teratas pada tahun 2020 2021 (BeritaSatu.com).

Instagram menjadi salah satu yang terbaik dalam hal promosi dibandingkan dengan media sosial lainnya karena Instagram lebih terfokus pada gambar dan video, selain itu Instagram juga memiliki fitur "business profile" yang gratis, dan sangat membantu pelaku usaha untuk mendapatkan statistik dari postingan dan kunjungan konsumen. Selain itu Indonesia merupakan pengguna Instagram terbanyak ke 4 dunia (Hootsuite/We Are Social). Penggunaan yang mudah dan jangkauan konsumen yang luas, terutama di Indonesia membuat Instagram sangat menjanjikan untuk digunakan sebagai media promosi.

Meskipun akses yang mudah serta pengetahuan yang cukup terhadap media sosial, masih banyak dari masyarakat Jl. Beringin Kelurahan Pamulang Barat yang masih belum memanfaatkan media sosial sebagai media promosi usaha mereka. Sosialisasi terhadap pemanfaatan media sosial sebagai media promosi usaha menjadi salah satu upaya untuk meningkatkan kesadaran masyarakat dalam pemanfaatan media sosial sebagai media promosi.

Teknologi yang terus berkembang memberikan banyak dampak positif maupun negatif bagi pelaku UMKM, terutama dalam promosi. Pemanfaatan teknologi sebagai sarana promosi sangat meningkatkan efisiensi dan efektivitas dalam memasarkan produk/jasa. Namun demikian, kurangnya perhaitan masyarakat terhadap kebermanfaatan teknologi menyebabkan banyaknya pelaku UMKM yang masih belum menyadari hal tersebut sehingga mereka tertinggal dan kurang bersaing. Termasuk di antaranya adalah pelaku UMKM di Jl. Beringin Kelurahan Pamulang Barat.

Pelaku UMKM di Jl. Beringin Kelurahan Pamulang Barat masih dominan mengandalkan promosi "mulut ke mulut" sehingga cakupan pasarnya tidak terlalu luas sebatas masyarakat sekitar atau kerabat. Dengan adanya keterbatasan dalam promosi, 
pada akhirnya kami memutuskan untuk melakukan kegiatan PKM yang kami beri judul "Pemanfaatan Media Sosial Sebagai Media Promosi Usaha Tingkat UMKM di Kelurahan Pamulang Barat”.

\section{Metode Pelaksanaan}

Pengabdian Kepada Masyarakat (PKM) bertujuan untuk membantu masyarakat dalam proses pemberdayaan/pengembangan diri dalam rangka mencapai perikehidupan yang lebih maju, adil, dan sejahtera. Termasuk di dalamnya adalah usaha untuk meningkatkan kemampuan dalam melakukan promosi usaha dengan menggunakan media sosial pada Bapak/Ibu warga Jl. Beringin, Kel. Pamulang Barat.

Dalam pelaksanaan Pengabdian Kepada Masyarakat (PKM) yang akan dilaksanakan di Jl. Beringin, Kel. Pamulang terdapat beberapa tujuan yang ingin dicapai, diantaranya:

1. Mengenalkan aplikasi media sosial kepada Bapak/Ibu pelaku usaha di Jl.Beringin, Kel. Pamulang Barat.

2. Memotivasi Bapak/Ibu pelaku usaha di Jl.Beringin, Kel. Pamulang Barat agar mampu menggunakan aplikasi media sosial.

3. Menambah kompetensi Bapak/Ibu pelaku usaha agar lebih aktif berkreasi sesuai dengan perkembangan zaman.

\section{Hasil dan Pembahasan}

Desain Pemecahan Masalah yang dilakukan pada saat kegiatan pengabdian kepada masyarakat adalah memberikan kemampuan dasar dan teknik kepada para pelaku usaha agar mereka mampu mempromosikan usaha dengan cakupan yang lebih luas, dari pada hanya melakukan promosi dari mulut ke mulut. Berikut ini adalah desain pemecahan masalah pada obyek PKM, yaitu:

1. Pembukaan materi penggunaan Aplikasi Media Sosial.

2. Penyampaian materi peran Aplikasi Media Sosial dalam membantu promosi usaha.

3. Contoh penggunaan Aplikasi Media Sosial.

4. Tanya jawab peserta.

5. Penutupan.

Desain pemecahan masalah diatas dapat berubah sesuai kondisi di lapangan dan mengikuti kebutuhan dari para pelaku usaha. Berikut adalah susunan acara PKM yang telah dilaksanakan (Lihat Tabel 1):

Tabel 1. Pelaksanaan Kegiatan PKM

\begin{tabular}{|cll|}
\hline WAKTU & \multicolumn{1}{c|}{ ACARA } & \multicolumn{1}{c|}{ PELAKSANA } \\
\hline 08.00 s.d 08.15 & Pendataan Kehadiran Peserta & Pengabdi/Peserta \\
08.15 s.d 08.20 & Pembukaan dan Doa & Drs. H. Jazuli Mukhtar, M.M. \\
08.20 s.d 08.25 & Sambutan Ketua Dosen Pendamping & Santosa Wijayanto, S.T., M.Kom. \\
& PKM & \\
08.25 s.d 08.30 & Sambutan oleh Bapak Ketua RW 07 & Nurhadi \\
08.30 s.d 08.35 & Sambutan oleh Bapak Ketua RT 001 & Syaiful \\
08.35 s.d 09.35 & Presentasi pengenalan dan pelatihan & Faishal Rahman dan Ade \\
& Aplikasi Media Sosial & Suhendra \\
\hline
\end{tabular}


Vol. 1. No. 2, Agustus 2021

\begin{tabular}{|cll|}
\hline WAKTU & \multicolumn{1}{c|}{ ACARA } & \multicolumn{1}{c|}{ PELAKSANA } \\
\hline 09.35 s.d 09.45 & Sesi tanya jawab & Faishal Rahman dan Ramadhan \\
& & Ari Saputra \\
09.45 s.d 10.00 & Penutupan dan foto bersama & Pengabdi dan Peserta \\
\hline
\end{tabular}

\section{Penyampaian Materi}

Materi "Pemanfaatan Media Sosial Sebagai Media Promosi" dilakukan dengan metode presentasi langsung dan daring. Materi yang disampaikan meliputi manfaat dan kekurangan media sosial, statistik pengguna media sosial di Indonesia, hingga fitur Insight pada Instagram.

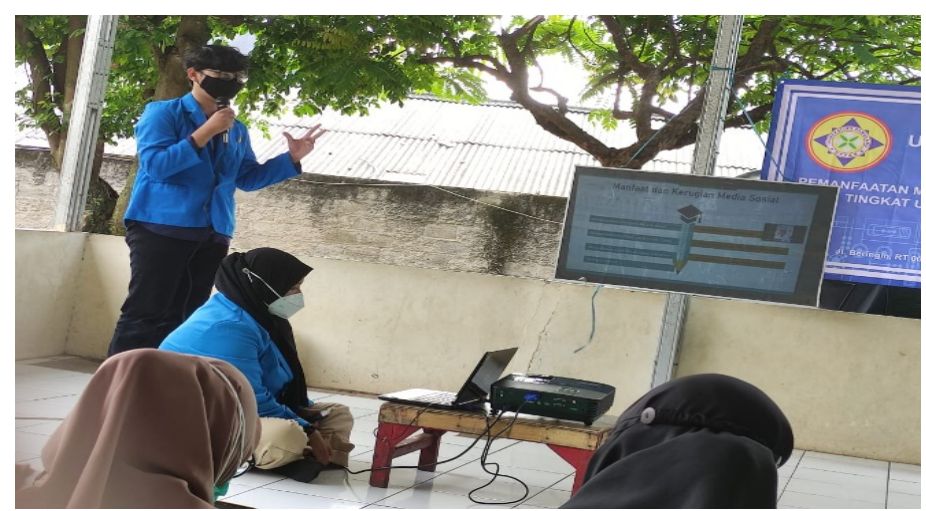

Gambar 1. Penyampaian Materi
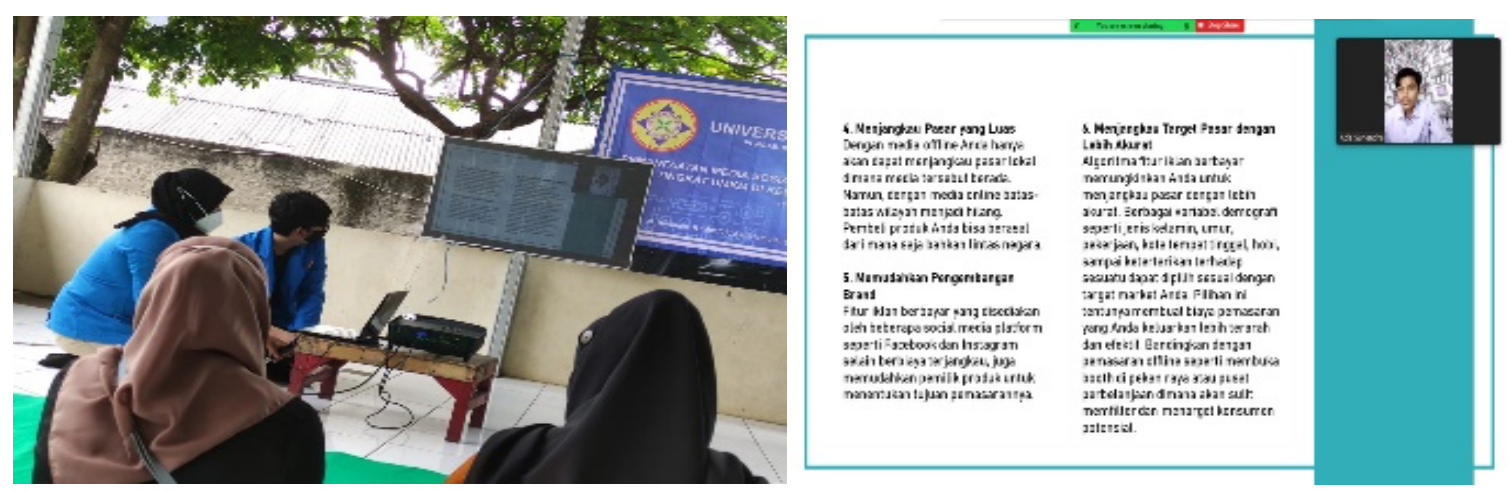

Gambar 2. Penyampaian Materi Secara Daring

\section{Demo Implementasi Media Sosial}

Peserta diberikan arahan langsung secara step-by-step tentang bagaimana cara menggunakan media sosial (Instagram) sebagai media promosi.

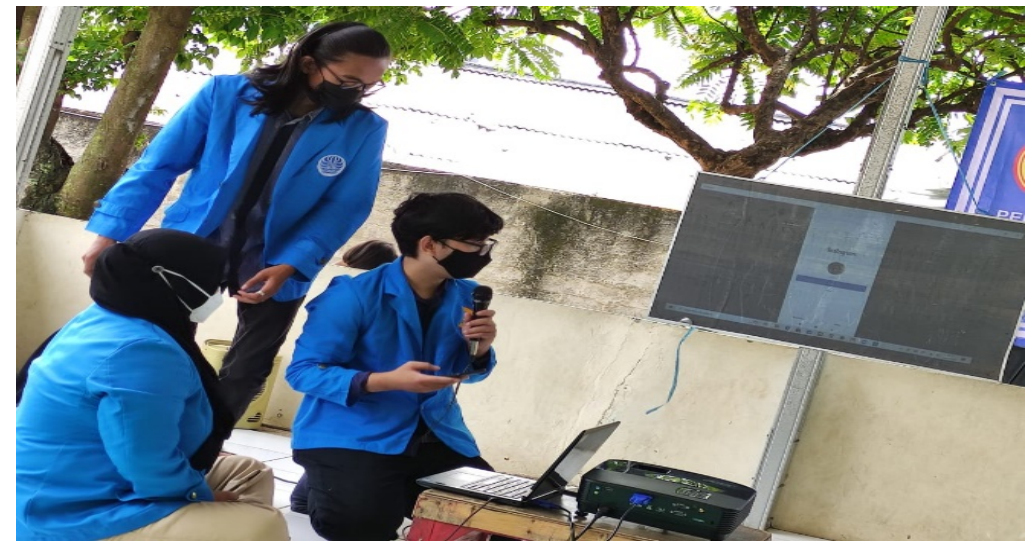

Gambar 3. Demo Implementasi Instagram sebagai Media promosi 

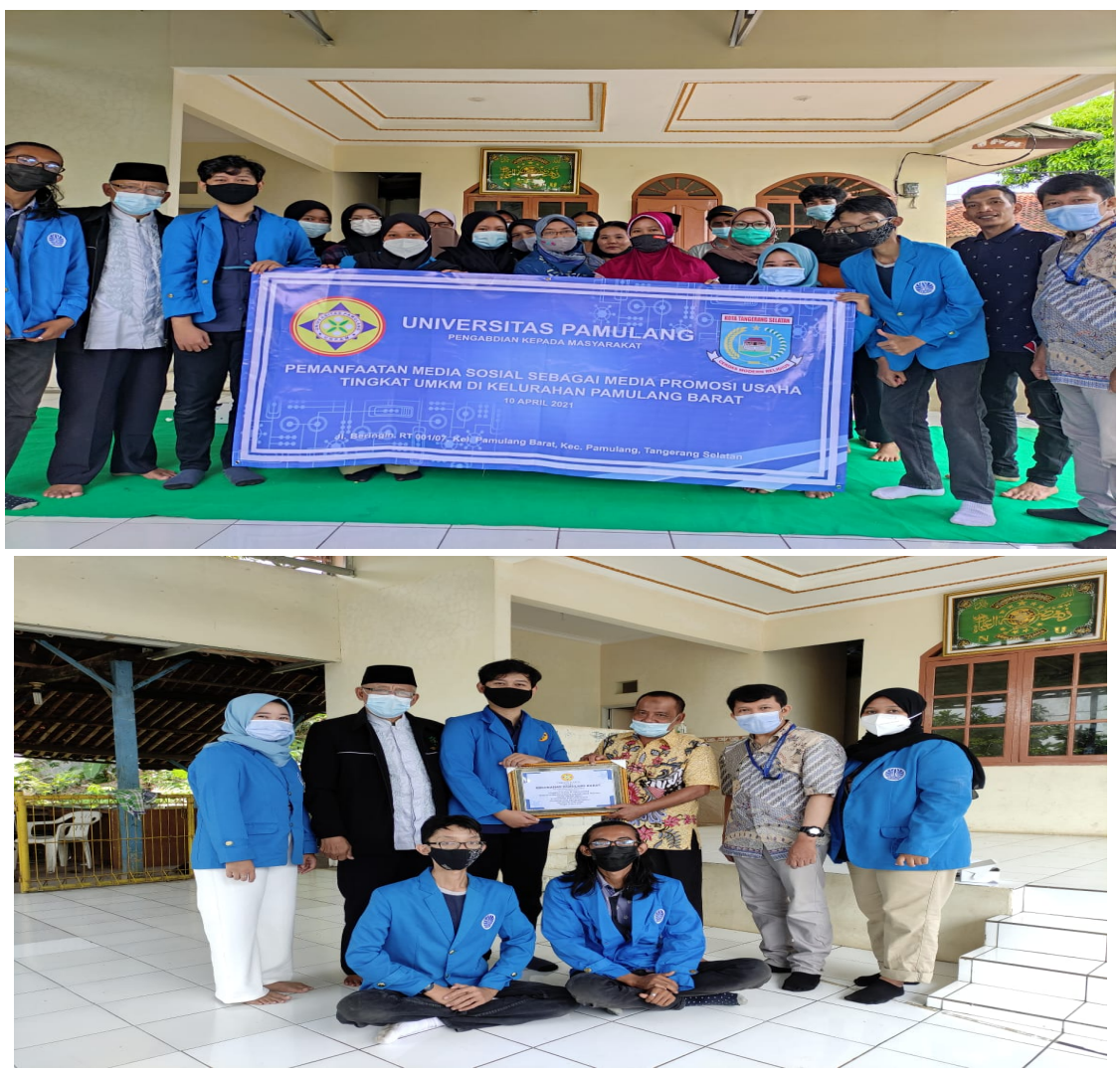

Gambar 5. Dokumentasi penyerahan plakat dan foto bersama

Kegiatan pengabdian kepada masyarakat diharapkan dapat memberikan manfaat terutama pada masyarakat yang dilakukan oleh Tim Fakultas Teknik Sistem Informasi Universitas Pamulang. Kegiatan pengabdian kepada masyarakat dapat menumbuhkan rasa keingintahuan para siswa SMK Bina Putra Mandiri mengenai Content Management System (CMS) sehingga dapat diimplementasikan dalam pembelajaran mengingat kompetensi keahlian siswa yang selaras dengan materi ini. Disamping itu kegiatan ini juga dapat menambah pengetahuan bagi mahasiswa untuk melatih menggunakan ilmu yang telah didapat selama perkuliahan.

\section{Kesimpulan}

Dari kegiatan Pengabdian Kepada Masyarakat ini dapat diambil kesimpulan bahwa:

1. Masyarakat Jl. Beringin Kelurahan Pamulang Barat sudah mengetahui media sosial, namun belum memahami cara menggunakan media sosial sebagai media promosi usaha mereka.

2. Analisis pasar dapat didapatkan dengan lebih mudah dan akurat dengan menggunakan fitur-fitur yang terdapat pada aplikasi media sosial.

3. Untuk memastikan bahwa media yang masyarakat gunakan adalah yang paling relevan dan terbaik, masyarakat perlu membiasakan diri untuk terus mencari informasi mengenai perkembangan teknologi informasi.

4. Maka dari itu mahasiswa Sarjana Komputer Universitas Pamulang diharapkan dapat berupaya melakukan kontribusi dalam melaksanakan kegiatan pengabdian kepada masyarakat. 


\section{Ucapan Terimakasih}

Penulis dengan segala kerendahan hati menyampaikan ucapan terima kasih kepada:

1. Bapak Dr. H. E. Nurzaman, AM., M.M., M.Si. selaku Rektor Universitas Pamulang.

2. Bapak Dede Supriyadi, S.Kom., M.Kom. selaku Ketua Prodi Sistem Informasi S1 Universitas Pamulang.

3. Bapak Dr. Ali Maddiansyah, S.E., M.M. selaku Kepala LPPM Universitas Pamulang.

4. Bapak Dr. Yunus, S.Pd.I., M.Pd.I. selaku Koordinator LPPM Prodi Sistem Informasi Universitas Pamulang.

5. Bapak Salman Farizy, S.Kom., MCSE, MVP. selaku Dosen mata kuliah Kerja Praktek.

6. Bapak Drs. H. Jazuli Mukhtar, M.M. dan Bapak Santosa Wijayanto, S.T., M.Kom. selaku Dosen Pembimbing.

7. Rekan-rekan mahasiswa Program Studi Sistem Informasi Universitas Pamulang.

\section{Referensi}

Republik Indonesia. Undang-Undang Nomor 20 tahun 2008 tentang Usaha Mikro, Kecil, dan Menengah.

Maoyan et al. 2014. Consumer Purchase Intention Research Based on Social Media Marketing. International Journal of Business and Social Science. Vol. 5 No.10 (1), p.92-97

Dahono, Yudo. 2021. Data: Ini Media Sosial Paling Populer di Indonesia 2020-2021. Sumber https://www.beritasatu.com/digital/733355/data-ini-media-sosialpaling-populer-di-indonesia-20202021 Diakses [26 April 2021]

DATAREPORTAL. 2021. Digital 2021 : Indonesia. Sumber https://datareportal.com/reports/digital-2021-indonesia Diakses [26 April 2021]

Hootsuite, We Are Social. 2021. Instagram users by country. Sumber https://www.businessofapps.com/data/instagram-statistics/ Diakses [26 April 2021] 